\title{
Capsule Summary of Buitron de la Vega et al., "It's like a mirror image of my illness". Exploring Patient Perceptions About Illness Using Health Mind Mapping: a Qualitative Study
}

\author{
Richard M. Frankel, Ph.D. \\ Regenstrief Institute, Indiana University School of Medicine, Indianapolis, IN, USA.
}

J Gen Intern Med 33(10): 1784

DOI: $10.1007 / \mathrm{s} 11606-018-4613-5$

(๑) Society of General Internal Medicine 2018

I n a classic 1977 article entitled, "From utterance to text: The bias of language in speech and writing", 1 David Olson traces the gradual transition from spoken to written language starting with the invention of the Greek alphabet and reaching its zenith in the eighteenth century British essayist tradition. Olson argues that the oral tradition, which was the gold standard for trustworthy communication for centuries, was replaced by written texts as the repository and arbiter of truth. For the professions, medicine, the law, and education, this meant a cultural shift from learning by speaking to learning from written texts.

The emphasis on textual learning for medicine has been profound. Medical education, record keeping, and legal aspects of the physician patient relationship are all enshrined in written documents. As a consequence, other non-written forms of knowing, such as art, spoken stories, dreams, and other imaginative devices, appear, if at all, stripped of their lived socio-emotional context in the form of SOAP notes or other templated ways of storing information.

Stories and in particular pictures, which from a linguistic point of view are irreducible forms of social interaction, certainly have a history in medicine, and particularly within psychiatry. In the modern era, authors from George Engel who introduced the biopsychosocial model, ${ }^{2}$ to Arthur Kleinman who focused on cultural differences in patients' explanatory models, ${ }^{3}$ to Rita Charon, who coined the term "narrative medicine," as a way of calling attention to the importance of stories in the doctor patient relationship, ${ }^{4}$ have treated stories as texts, as a way of knowing and understanding the personhood of the patient beyond diagnosing and treating her disease(s).

The paper by Buitron de la Vega and colleagues, and Health Mind Mapping fits well within the tradition of attending to stories and the lived experiences of patients, helping them to express their concerns using multiple modalities like drawing. ${ }^{5}$ The title of the paper, "It's like a mirror image of my illness". Exploring patient perceptions about illness using Health Mind Mapping: A qualitative study," and especially the phrase "Health Mind Mapping," suggests an approach that is vaguely occult or neuroscience-like; however, it is neither. HMM is a technique to help patients articulate their concerns using a combination of drawing and semi structured interview questions. In this regard, it follows a tradition in family systems medice of having patients draw a circle and locate family relationships in time and space rather than a genogram based on lots of closed-ended questions. ${ }^{6}$ The authors do an admirable job of illustrating how the technique works and its benefits to patients, and presumably their physicians.

This is a small qualitative study that raises as many questions as it answers, but if a picture is worth a thousand words, this study is worth reading, reflecting on and learning from.

Corresponding Author: Richard M. Frankel, Ph.D.; Regenstrief Institute, Indiana University School of Medicine, Indianapolis, IN, USA (e-mail: rfrankel@iupui.edu).

\section{Compliance with Ethical Standards:}

Conflict of Interest: The author declares that he does not have a conflict of interest.

\section{REFERENCES}

1. Olson D. From utterance to text: the bias of language in speech and writing. Harv Educ Rev 1977(47):257-81.

2. Engel GL. The need for a new medical model: a challenge for biomedicine. Science 1977;196:129-36.

3. Kleinman A. Patients and healers in the context of culture. Berkeley: University of California Press; 1980.

4. Charon R. Narrative Medicine: Honoring the Stories of Illness. New York: Oxford Press; 2006.

5. de la Vega PB, Coe C, Paasche-Orlow MK, Clark JA, Waite K, Sanchez MJ, Armstrong E, Bokhour BG. "It's like a mirror image of my illness". Exploring patient perceptions about illness using Health Mind Mapping: a qualitative study. J Gen Intern Med. https://doi.org/10.1007/s11606018-4557-9.

6. Thrower SM, Bruce WE, Walton RF. The family circle method for integrating family systems concepts in family medicine. J Fam Pract 1982;15(3):451-7

Published online August 20, 2018 